\title{
Pulse wave velocity: why is it important to know to estimate?
}

\author{
Anilkumar K. Reddy, George E. Taffet \\ Department of Medicine, Baylor College of Medicine, Houston, TX 77030, USA.
}

Correspondence to: Dr. George E. Taffet, Department of Medicine, Baylor College of Medicine, One Baylor Plaza, Houston, TX 77030, USA. E-mail: gtaffet@bcm.edu; Dr. Anilkumar K. Reddy, Department of Medicine, Baylor College of Medicine, One Baylor Plaza, Houston, TX 77030, USA. E-mail: areddy@bcm.edu

How to cite this article: Reddy AK, Taffet GE. Pulse wave velocity: why is it important to know to estimate? J Cardiovasc Aging 2022;2:10. https://dx.doi.org/10.20517/jca.2021.36

Received: 9 Dec 2021 Accepted: 15 Dec 2021 Published: 5 Jan 2022

Academic Editor: Ali J. Marian Copy Editor: Xi-Jun Chen Production Editor: Xi-Jun Chen

Optimal ventriculo-vascular coupling is critical for proper performance of the left ventricle. This depends on the pulsatile (frequency) components of the arterial pressure/flow reflected from the periphery to arrive at the aortic root after the aortic valve closes. Optimal coupling occurs when the young and normal aorta/arterial wall primary components (i.e., collagen, elastin, and smooth muscle) work efficiently. However, with age or disease (atherosclerosis, hypertension, etc.), the wall structure can be modified, decreasing aortic compliance (increasing aortic stiffness). As the stiffer aorta is distended by the bolus of blood ejected from the left ventricle, a higher pressure results. Additionally, the increased aortic stiffness may lead to the arrival of reflected waves from the periphery before the aortic valve closes, further increasing the load on the heart. Thus, aortic stiffness is an important risk factor for cardiovascular morbidity and mortality.

There are multiple ways to measure aortic stiffness; pulse wave velocity (PWV) is one such measure. PWV is defined as the ratio of "the distance between two aortic/arterial sites (D)" to "the difference in arrival times of the foot of the upstroke of pressure or flow velocity at the sites (foot-to-foot timing, PTT)" or PWV = D/PTT. In humans, PWV is estimated using Doppler blood flow velocity waveforms at carotid and femoral arterial sites (cfPWV). As described below, cfPWV is not straightforward, and its acceptance as a clinical measure has been slow. Methods to estimate PWV (ePWV) using age and mean arterial blood pressure as presented 
and analyzed by Heffernan et al. ${ }^{[1]}$ are a promising surrogate. The relationship between PWV and age and PWV and mean blood pressure are discussed here.

\section{PWV AND AGE}

The relationship between aging and arterial stiffness was described in the 1920 s by Bramwell and Hill ${ }^{[2]}$. They reported that carotid-to-radial PWV increased with age in normal individuals from $4.7 \mathrm{~m} / \mathrm{s}$ at 6 years of age to $8.5 \mathrm{~m} / \mathrm{s}$ at 66 years of age, exhibiting a curvilinear relationship. They noted that this relationship might not be valid under pathological conditions. Decades later, numerous studies confirmed that PWV increases with age, consistent with the arteries becoming stiffer ${ }^{[3-8]}$. These studies used different methods and different sites to measure PWV, including ascending aortic ${ }^{[3]}$, aortic-femoral ${ }^{[4-6]}$, brachial-radial and femoral$\operatorname{ankle}^{[5]}$, carotid-femoral ${ }^{[6-8]}$, and carotid-radial ${ }^{[7]}$ sites. Some studies reported a linear relationship between PWV and age ${ }^{[3-6]}$; others reported non-linear relationship ${ }^{[7,8]}$ where PWV increased to an even greater extent beyond 50 years of age $\mathrm{e}^{[7]}$. Additionally, differences between age-associated stiffening of the aorta and stiffening in peripheral arteries were recognized ${ }^{[9]}$.

\section{PWV, MEAN PRESSURE, AND DISTENDING PRESSURE}

Avolio et al. ${ }^{[5]}$ reported that while PWV was significantly correlated to mean arterial pressure (MAP = DAP $+1 / 3$ (SAP-DAP), the increases in PWV with increasing MAP were independent of age. This relationship of PWV and MAP to age has been confirmed by the study reported by the Reference Values for Arterial Stiffness Collaboration ${ }^{[8]}$. Yet, as described above, all these studies used arrival times of the foot of the upstroke of flow velocity to obtain cfPWV. The use of foot-to-foot (pressure or flow velocity) arrival times means PWV is measured when diastolic pressure is the distending pressure. As PWV is proportional to the pressure in the vessel ${ }^{[10,11]}$ when it is measured, PWV measured at diastolic pressure is lower than PWV measured at any other time within the cardiac cycle. This results in the underestimation of aortic stiffness and the actual load on the heart. The extent of this underestimation is greatest when the arteries are the stiffest in both human studies ${ }^{[12,13]}$, and animal studies (mice ${ }^{[14]}$ and rats ${ }^{[15]}$ ). Theoretically, if aortic stiffness was increased with no other change in the system, then systolic blood pressure would increase and diastolic pressure decrease with minimal change in mean pressure. Thus, PWV assessment throughout the cardiac cycle is therefore vitally important.

The equations used by Heffernan et al. ${ }^{[1]}$ include age ${ }^{2}$ and mean pressure ${ }^{2}$. The two "squared" factors represent the non-linear relationship between PWV and age and pressure. Furthermore, they looked at two different estimation equations, both "best fits" from differing populations. While the equations estimate $\mathrm{PWV}$, we wanted to underscore that the gold standard cfPWV was measured at diastolic pressure. Further, mean pressure includes the systolic pressure, more an output of arterial stiffness than a determinant.

\section{OTHER ISSUES WITH ACTUAL MEASUREMENT OF PWV IN PEOPLE}

Noninvasively measured cfPWV is used extensively and accepted as the clinical "gold standard", but cfPWV has had slow uptake in the clinic. This PWV measurement, affected by experimental and methodological factors apart from physiological and pathological factors, may not be as robust as most "gold standards". There are ambiguous/confounding issues reported in some studies ${ }^{[16,17]}$ caused by the following limitations.

\section{Carotid/brachial and ankle/femoral arterial sites $t$ include vessel segments that do not have the same properties as the aorta}

PWV measurements in humans using carotid-femoral ${ }^{[18,19]}$, $\operatorname{carotid}$ radial $^{[20]}$, brachial-femoral ${ }^{[21]}$, or brachialankle ${ }^{[22]}$ arterial sites include vessels with properties very different from the aorta. Using a multi-sensor pressure catheter, Latham et al. ${ }^{[23]}$ showed PWV increases from $\sim 4.4 \mathrm{~m} / \mathrm{s}$ in the ascending aorta to $\sim 9.2 \mathrm{~m} / \mathrm{s}$ 
in the lower abdominal aorta in non-hypertensive humans ( $\sim 42$ years). The femoral and brachial arteries have PWV 3-4 times higher than the aorta ${ }^{[24]}$, and including segments of these arteries elevates PWV values leading to misinterpretation. "Aortic PWV" techniques that include carotid artery, brachial artery, and femoral artery segments overestimate aortic PWV by $\sim 34 \%^{[25]}, \sim 92 \%$, and $\sim 105 \%^{[24]}$, respectively $v s$. the true aorta $^{[23]}$ in age-matched subjects.

\section{Estimating the separation distance (D) between the two arterial sites is also difficult} Girerd et al ${ }^{[17]}$ compared different estimation techniques for D - Direct (d); Real (0.8 d); Subtracted (1.04 d $0.11 \mathrm{BH}$ - 0.02); Estimated (BH/4 + 7.28); (where d - direct length between carotid-femoral sites, $\mathrm{BH}$ - body height). Depending upon the technique used to estimate D, PWV values varied by $40 \%(11.6 \mathrm{~m} / \mathrm{s}, 9.3 \mathrm{~m} / \mathrm{s}$, $8.3 \mathrm{~m} / \mathrm{s}$, and $9.2 \mathrm{~m} / \mathrm{s}$ ), respectively, in the same patients. Thus, even the estimation of D leads to ambiguity in the measured PWV values.

\section{Use of non-simultaneously measured signals at two arterial sites to calculate PWV (errors caused by transients in heart rate)}

Measurement of PWV using non-simultaneous electrocardiogram R-wave peak as reference limits accuracy, especially during transients in heart rate caused by irregular cardiac cycles or variations in heart rate. In mice, we showed that PWV calculated from non-simultaneously measured waveforms was significantly less reproducible compared to that calculated from simultaneously measured waveforms from two sites ${ }^{[26]}$.

\section{OVERALL CONCLUSION}

Given the importance of arterial stiffness and the technical challenges with its accurate measurement, efforts to estimate PWV and validate those estimation tools are to be applauded. However, given the wide variation between estimated PWV and measured PWV described by Heffernan et al. ${ }^{[1]}$, the continued search for an easily applicable tool or technique to assess aortic stiffness remains a top priority.

\section{DECLARATIONS}

Authors' contributions

Conceived and wrote the paper: Reddy AK, Taffet GE

\section{Availability of data and materials}

Not applicable.

\section{Financial support and sponsorship}

None.

\section{Conflicts of interest}

Both authors declared that there are no conflicts of interest.

\section{Ethical approval and consent to participate}

Not applicable.

\section{Consent for publication}

Not applicable.

\section{Copyright}

(c) The Author(s) 2022. 


\section{REFERENCES}

1. Heffernan K, Stoner L, Meyer M, et al. Associations between estimated and measured carotid-femoral pulse wave velocity in older black and white adults: the atherosclerosis risk in communities (ARIC) study. J Cardiovasc Aging. Forthcoming 2022. DOI

2. Bramwell JC, Hill A. Velocity of the transmission of pulse-wave and elasticity of arteries. Lancet 1922;199:891-2. DOI

3. Gozna ER, Marble AE, Shaw A, Holland JG. Age-related changes in the mechanics of the aorta and pulmonary artery of man. J Appl Physiol 1974;36:407-11. DOI PubMed

4. Simonson E, Nakagawa K. Effect of age on pulse wave velocity and "aortic ejection time" in healthy men and in men with coronary artery disease. Circulation 1960;22:126-9. DOI PubMed

5. Avolio AP, Chen SG, Wang RP, Zhang CL, Li MF, O'Rourke MF. Effects of aging on changing arterial compliance and left ventricular load in a northern Chinese urban community. Circulation 1983;68:50-8. DOI PubMed

6. Vaitkevicius PV, Fleg JL, Engel JH, et al. Effects of age and aerobic capacity on arterial stiffness in healthy adults. Circulation 1993;88:1456-62. DOI PubMed

7. McEniery CM, Yasmin, Hall IR, Qasem A, Wilkinson IB, Cockcroft JR; ACCT Investigators. Normal vascular aging: differential effects on wave reflection and aortic pulse wave velocity: the Anglo-Cardiff Collaborative Trial (ACCT). J Am Coll Cardiol 2005;46:1753-60. DOI PubMed

8. Reference Values for Arterial Stiffness' Collaboration. Determinants of pulse wave velocity in healthy people and in the presence of cardiovascular risk factors: 'establishing normal and reference values'. Eur Heart J 2010;31:2338-50. DOI PubMed PMC

9. Boutouyrie P, Laurent S, Benetos A, Girerd XJ, Hoeks AP, Safar ME. Opposing effects of ageing on distal and proximal large arteries in hypertensives. J Hypertens Suppl 1992;10:S87-91. PubMed

10. Armentano RL, Levenson J, Barra JG, et al. Assessment of elastin and collagen contribution to aortic elasticity in conscious dogs. Am J Physiol 1991;260:H1870-7. DOI PubMed

11. Meinders JM, Hoeks AP. Simultaneous assessment of diameter and pressure waveforms in the carotid artery. Ultrasound Med Biol 2004;30:147-54. DOI PubMed

12. Hermeling E, Reesink KD, Kornmann LM, Reneman RS, Hoeks AP. The dicrotic notch as alternative time-reference point to measure local pulse wave velocity in the carotid artery by means of ultrasonography. J Hypertens 2009;27:2028-35. DOI PubMed

13. Hermeling E, Hoeks AP, Winkens MH, et al. Noninvasive assessment of arterial stiffness should discriminate between systolic and diastolic pressure ranges. Hypertension 2010;55:124-30. DOI PubMed

14. Reddy AK, Hartley CJ, Pham TT, Darlington G, Entman ML, Taffet GE. Young little mice express a premature cardiovascular aging phenotype. J Gerontol A Biol Sci Med Sci 2014;69:152-9. DOI PubMed PMC

15. Reddy AK, Entman ML, Taffet GE. Pulse wave velocity measured at end-diastole underestimates aortic stiffness. Circulation 2021;144:A10665.

16. Kaess BM, Rong J, Larson MG, et al. Aortic stiffness, blood pressure progression, and incident hypertension. JAMA 2012;308:875-81. DOI PubMed PMC

17. Girerd N, Legedz L, Paget V, et al. Outcome associations of carotid-femoral pulse wave velocity vary with different measurement methods. Am J Hypertens 2012;25:1264-70. DOI PubMed

18. Ben-Shlomo Y, Spears M, Boustred C, et al. Aortic pulse wave velocity improves cardiovascular event prediction: an individual participant meta-analysis of prospective observational data from 17,635 subjects. J Am Coll Cardiol 2014;63:636-46. DOI PubMed PMC

19. Mitchell GF, Hwang SJ, Vasan RS, et al. Arterial stiffness and cardiovascular events: the Framingham Heart Study. Circulation 2010;121:505-11. DOI PubMed PMC

20. Utescu MS, Couture V, Mac-Way F, et al. Determinants of progression of aortic stiffness in hemodialysis patients: a prospective longitudinal study. Hypertension 2013;62:154-60. DOI PubMed

21. Keehn L, Milne L, McNeill K, Chowienczyk P, Sinha MD. Measurement of pulse wave velocity in children: comparison of volumetric and tonometric sensors, brachial-femoral and carotid-femoral pathways. J Hypertens 2014;32:1464-9; discussion 1469. DOI PubMed PMC

22. Vlachopoulos C, Aznaouridis K, Terentes-Printzios D, Ioakeimidis N, Stefanadis C. Prediction of cardiovascular events and all-cause mortality with brachial-ankle elasticity index: a systematic review and meta-analysis. Hypertension 2012;60:556-62. DOI PubMed

23. Latham RD, Westerhof N, Sipkema P, Rubal BJ, Reuderink P, Murgo JP. Regional wave travel and reflections along the human aorta: a study with six simultaneous micromanometric pressures. Circulation 1985;72:1257-69. DOI PubMed

24. Avolio AP, Deng FQ, Li WQ, et al. Effects of aging on arterial distensibility in populations with high and low prevalence of hypertension: comparison between urban and rural communities in China. Circulation 1985;71:202-10. DOI PubMed

25. Pan FS, Yu L, Luo J, et al. Carotid artery stiffness assessment by ultrafast ultrasound imaging: feasibility and potential influencing factors. J Ultrasound Med 2018;37:2759-67. DOI PubMed

26. Reddy AK, Madala S, Jones AD, et al. Multichannel pulsed Doppler signal processing for vascular measurements in mice. Ultrasound Med Biol 2009;35:2042-54. DOI PubMed PMC 